\title{
Beaver tail liver: A rare anatomical variant
}

\author{
Ramakrishna Narra ${ }^{1}$, Sushil Kumar Kamaraju ${ }^{2}$ \\ From ${ }^{1}$ Professor, Department of Radiology, Katuri Medical College, ${ }^{2}$ Professor, Kamaraju Diagnostic Center, Guntur, Andhra Pradesh, India
}

$\mathrm{W}$ e report a case of 35-year-old male with abdominal pain who was presenting with burning micturition and incidentally found to have elongated left lobe of the liver. Computed tomography (CT) of abdomen done showed an elongated left lobe of the liver and extending in the perisplenic region.

A 35-year-old man presented with complaints of burning micturition for 1 month. On examination, vitals were stable with a pulse rate of $78 / \mathrm{min}$ and blood pressure of $120 / 85 \mathrm{mmHg}$. Blood investigation showed a mild elevation in the white blood cell count $(12,500$ cells $/ \mathrm{mL})$ with elevated neutrophils $(80 \%)$. Urine examination showed pus cells. Red blood cells casts with culture showing Escherichia coli. A CT of the abdomen was done to rule out the obstructive uropathy which revealed the features of cystitis. Incidentally, the left lobe of the liver was found to be elongated, extending across the midline to encircle the spleen (Fig. 1). This condition is known as beaver tail liver.

Beaver tail liver is an anatomical variant of the liver [1]. It is also known as the sliver of the liver. It is characterized by an elongated left lobe of the liver which extends across the midline along the anterior abdominal wall, often encircles, and touches the spleen. Some anatomists refer to this as an anatomical variant called appendix fibrosa hepatis, a fibrous band that attaches the left lobe of the liver to the diaphragm [2]. It resembles the tail of a beaver and hence the name. Beaver tail liver has a female predominance. It is composed of normal liver parenchyma. Hence, it has no additional risk of pathology. Beaver tail liver has to be differentiated from the splenic hematoma and splenic mass. It is difficult to identify this condition on ultrasound when its echogenicity is similar to the spleen. However, the color Doppler study helps in the identification of the normal hepatic and portal veins, thus differentiating it from

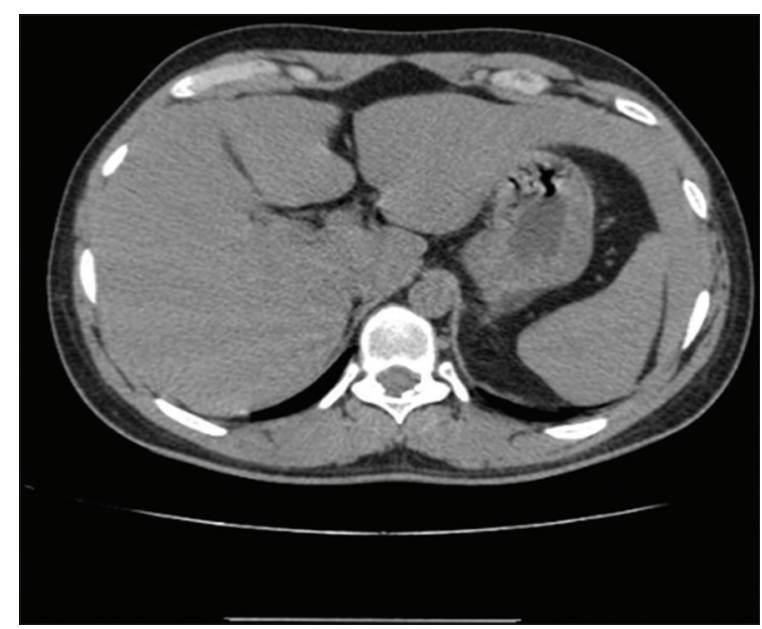

Figure 1: Axial computed tomography image of the abdomen showing elongated left lobe of the liver, encircling the spleen

the perisplenic hematoma or a renal mass. Beaver tail liver is more prone to injury in cases of trauma to the upper abdomen or chest and surgical procedures. Hence, it is very essential to know the significance of this condition to avoid unnecessary complications.

\section{REFERENCES}

1. Atalar MH, Karakus K. Beaver tail liver. Abdom Radiol (NY) 2017;22:1-2.

2. Xiang H, Han J, Ridley WE, Ridley LJ. Beaver tail liver: Anatomic variant. J Med Imaging Radiat Oncol 2018;62 Suppl 1:57.

Funding: None; Conflicts of Interest: None Stated.

How to cite this article: Narra R, Kamaraju SK. Beaver tail liver: A rare anatomical variant. Indian J Case Reports. 2020; 6(10):604.

\section{Access this article online}

Received - 30 September 2020 Initial Review - 17 October 2020 Accepted - 20 October 2020

DOI: $10.32677 /$ IJCR.2020.v06.i10.019
Quick Response code

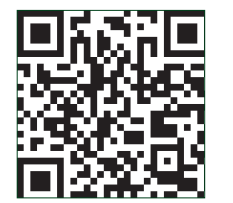

Correspondence to: Dr. Ramakrishna Narra, Flat No: 30, Venkatesh Estate Apartment, 1/2 Chandramoulinagar, Guntur - 522 007, Andhra Pradesh, India. E-mail: narra.ramki29@gmail.com

(C) 2020 Creative Commons Attribution-NonCommercial 4.0 International License (CC BY-NC-ND 4.0). 